\title{
Hypothalamic and pancreatic lesions with diabetes mellitus
}

\author{
SAMRUAY SHUANGSHOTI ${ }^{1}$ AND PRASERT SAMRANVEJ \\ From the Department of Pathology, Faculty of Medicine, \\ Chulalongkorn University, Bangkok, Thailand
}

SYNOPSIS A case is reported of a neoplasm of mixed mesenchymal and neuroepithelial origin consisting of plasmacytoma, lymphoma, ganglioneuroma, and astrocytoma in the same mass. The tumour arose in the hypothalamus of a 43 year old diabetic woman who also had alpha cell hyperplasia and beta cell hypoplasia of the islets of Langerhans. It is suggested that both hypothalamic and pancreatic lesions produced diabetes mellitus in this patient.

The manifestations of destruction of the hypothalamus have been frequently investigated in animals but the opportunity to study human lesions is rare. In this communication we describe a case of a hypothalamic neoplasm of mixed mesenchymal and neuroepithelial origin with cellular abnormalities of the islets of Langerhans. The lesions are considered to be the cause of disturbances of the carbohydrate metabolism in this instance. To our knowledge, no previous example has been recorded of combined hypothalamic and pancreatic lesions associated with diabetes mellitus.

\section{CASE REPORT}

Two years before admission to hospital, this married woman, aged 43 years, first experienced hyperphagia and polyuria. The progressive symptoms were severe during the period of two months before admission. One month before admission she had intermittent diffuse headache, pitting oedema of the lower limbs, anorexia, nausea, vomiting, mental confusion, and transient loss of consciousness. These symptoms were relieved occasionally by medical treatment. On the day of admission, she suffered respiratory difficulty and hyperpyrexia. There was no history of diabetes mellitus in her family. The patient had had 11 pregnancies, which included one

1 Address for reprints: Dr Samruay Shuangshoti, Department of Pathology, Faculty of Medicine, Chulalongkorn University, Bangkok 5, Thailand.

(Accepted 29 April 1975.) abortion, two episodes of intrauterine fetal death one neonatal death, and seven living children.

In hospital, the range of the vital signs was recorded as follows: body temperature, 37.5 to $39.5^{\circ} \mathrm{C}$; pulse rate, 70 to $130 / \mathrm{min}$; respiratory rate, 20 to $40 / \mathrm{min}$; and blood pressure, $60 / 20$ to $130 / 70 \mathrm{mmHg}$. The obese and comatose patient responded only to painful stimulation. The pupil, which was $4 \mathrm{~mm}$ in diameter, was reactive to light. The eye-ground could not be examined because of cataract. The tendon reflexes were absent.

Routine laboratory investigations showed a haemoglobin concentration of $90 \mathrm{~g} / 1$ and a leucocyte count of $16.45 \times 10^{9} / 1$ with $64 \%$ of neutrophils and $36 \%$ of lymphocytes. Urinalysis revealed 'one plus' of sugar, a trace of protein, and a few granular casts/high power microscope field. The daily volume of urine ranged from 150 to $1200 \mathrm{ml}$. Blood chemical studies showed the following values: blood urea nitrogen $8.8-11.0 \mathrm{nmol} / \mathrm{l}(53-66 \mathrm{mg} / \mathrm{dl})$; creatinine 36.24-53.4 $\mu \mathrm{mol} / 1(4.1-6.6 \mathrm{mg} / \mathrm{dl})$; fasting glucose $22.5 \mathrm{mmol} / \mathrm{l}(405 \mathrm{mg} / \mathrm{dl})$; sodium $150-160 \mathrm{mmol} / \mathrm{l}$ (normal, 135-145 mmol/l); chloride 114-130 mmol/l. and potassium $2.0-3.8 \mathrm{mmol} / 1$. Blood $\mathrm{pH}$ was 7.12 . The pressure of the clear and colourless cerebrospinal fluid in a lumbar puncture was $170 \mathrm{~mm}$ CSF. The fluid contained 57 lymphocytes $/ \mathrm{mm}^{3}$, and 1.37 $\mathrm{g} / \mathrm{l}$ of protein.

The clinical impression was diabetic acidosis with coma. The supportive treatment included intravenous administration of insulin and normal saline solution. Body temperature and blood pressure fluctuated, suggesting that the patient also had septic shock. Corticosteroid and antibiotics were 

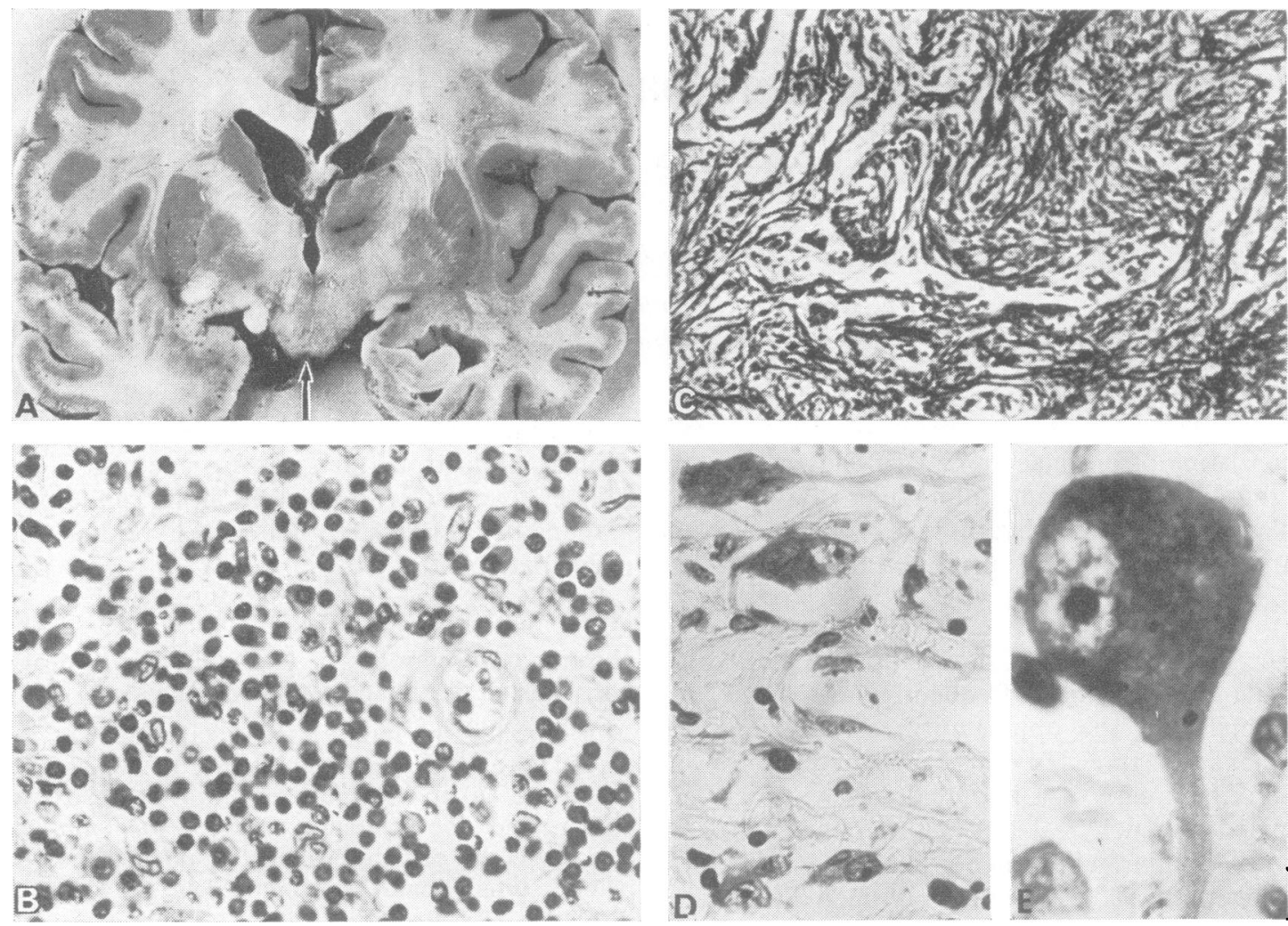

FIG. 1 A. Coronal section of the brain showing tumour (arrow) occupying the hypothalamus. B. Many plasma cells and lymphocytes are clustered around a small blood vessel. $H$ and $E, \times 330$. C. Numerous reticulin fibres are scattered in the area of plasma cells and lymphocytes. Wilder's stain, $\times 80 . \mathrm{D}$. A few abnormal neurones in the tumour are illustrated. Note nuclei with prominent nucleoli, and Nissl's bodies in the cytoplasm. Cresyl violet stain, $\times 330$. E. An abnormal ganglion cell with eccentric nucleus having a prominent centrally located nucleolus and abundant coarse cytoplasmic granules of the tigroid substance is further demonstrated. Cresyl violet stain, $\times 800$.

then given. The patient died five days after admission to hospital.

NECROPSY Tissue (A-8170) fixed in $10 \%$ formalin was embedded in paraffin, and the section was stained routinely with haematoxylin and eosin ( $\mathrm{H}$ and $\mathrm{E})$. Special stains were used as needed and included cresyl violet for Nissl's bodies, Wilder's reticulin stains, Mallory's phosphotungstic acid haematoxylin (PTAH), and Gomori's chromium haematoxylin phloxine.

The congested and oedematous brain, weighing $1150 \mathrm{~g}$, showed cerebellar tonsilar herniation. The hypothalamic region contained a rounded, grey rubbery mass, $2.0 \mathrm{~cm}$ in diameter (Fig. 1A). The anterior aspect of the mass lay just behind the optic chiasm. Laterally, it was bordered by the optic tracts. Its caudal part partially filled the interpeduncular fossa. The dorsal portion of the mass protruded minimally into the bottom of the third ventricle. Its anteroventral aspect was in continuity with the hypophyseal stalk. The mammillary bodies were not seen, and presumably were included within the mass. It was not possible to identify the precise nuclei which were involved by the lesion because the entire hypothalamus was occupied by the mass.

Microscopically, the mass was composed of multiple types of cells (Figs 1 and 2). Rounded cells with abundant violet or lavender perikaryon and eccentric nuclei having radially arranged granules of 


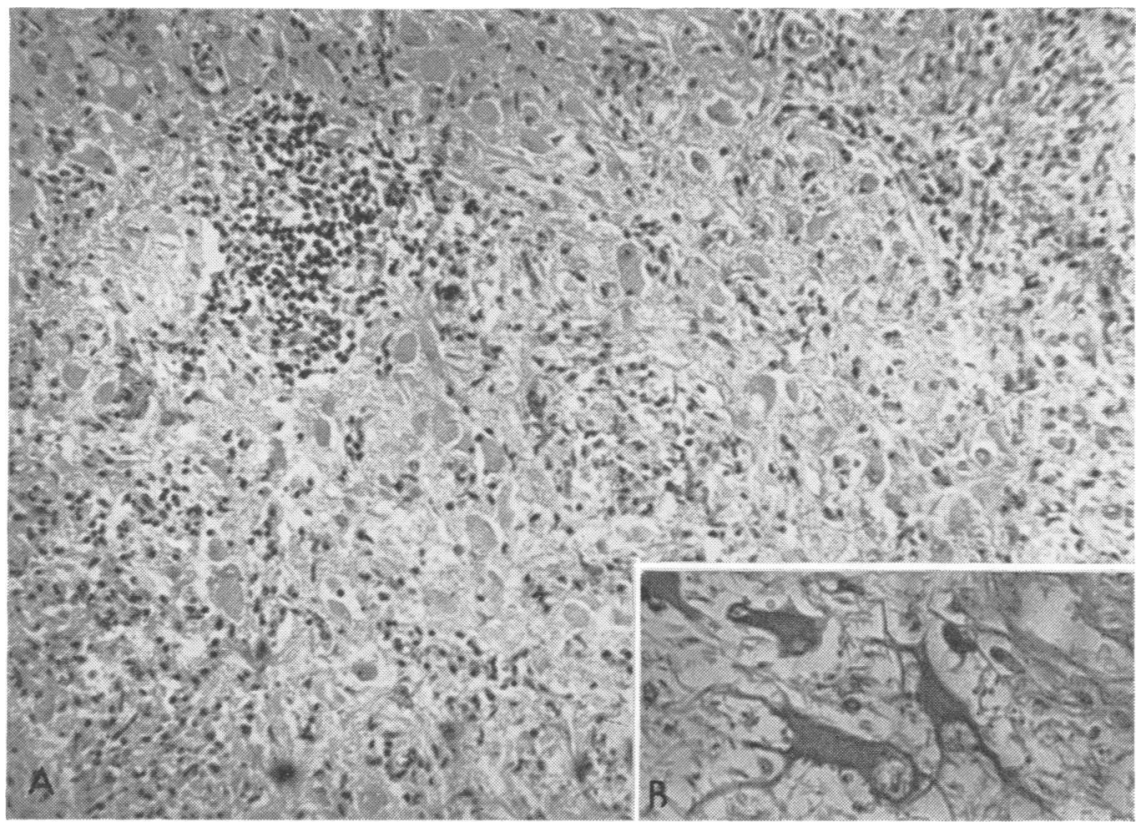

FIG. 2 A. Many astrocytes with angular outlines, homogeneous perikaryon, and eccentric nuclei are disseminated at random. Plasma cells and lymphocytes are also mingled. $H$ and $E, \times 70$. B (inset). A few astrocytes with coarse processes extending from the corners, and eccentric vesicular nuclei are further shown. PTAH, $\times 280$.

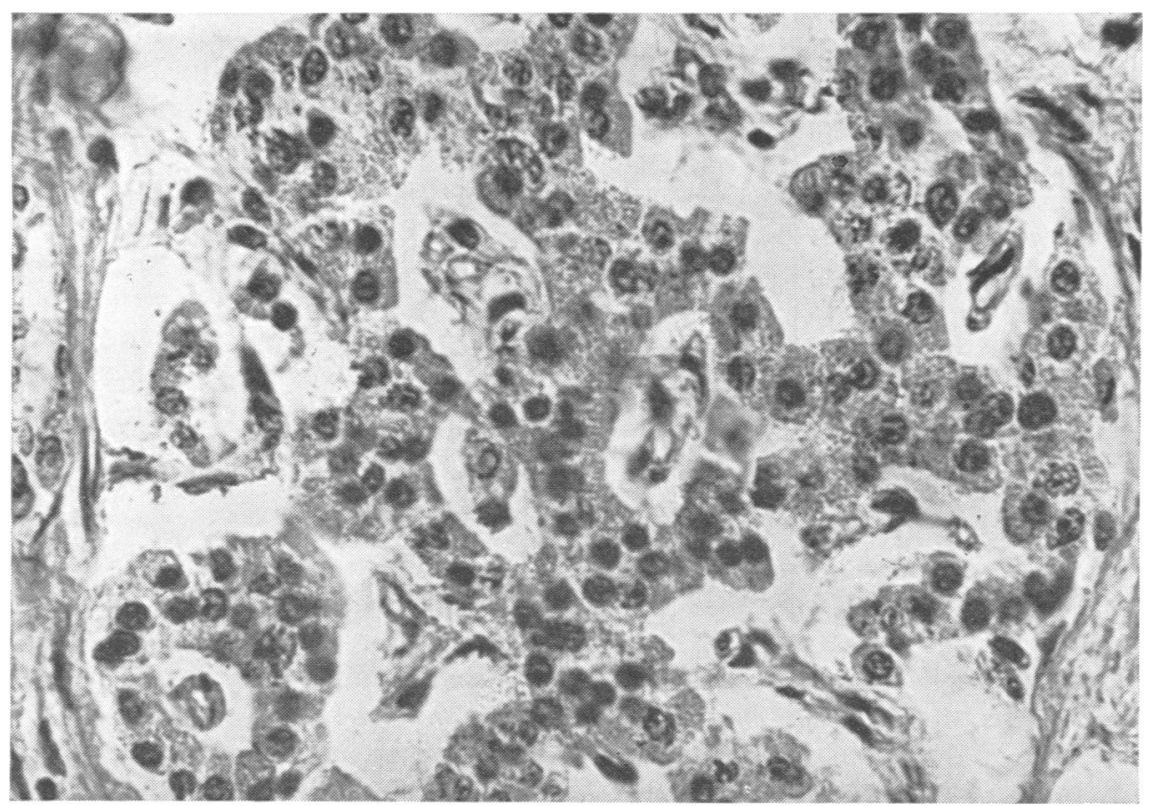

FIG. 3 An islet of Langerhans demonstrating many alpha cells having coarse acidophilic cytoplasmic granules. The latter are purple in Gomori's chromium haematoxylin phloxine stain. $H$ and $E, \times 280$. 
chromatin were interpreted as plasma cells (Fig. 1B). Small and rounded cells containing scant cytoplasm and hyperchromatic nuclei were considered to be lymphocytes (Fig. 1B). These plasma cells and lymphocytes were often clustered perivascularly, and there were numerous reticulin fibres among them (Fig. 1C). Some large bizarre cells with Nissl's bodies within the cytoplasm and nuclei with prominent nucleoli were regarded as neurones (Fig. 1D and E). There were still many large cells with angular outlines, abundant homogeneous cytoplasm, and eccentric vesicular nuclei (Fig. 2). Occasional coarse processes extended from the angular margin (Fig. 2B). They were interpreted as astrocytes. Reticulin fibres were absent or scantily present around some blood vessels in the zones of neuronal and astrocytic accumulation. Many blood vessels in the lesion had thick and hyalinized walls. The pituitary gland was normal.

The pancreas which weighed $70 \mathrm{~g}$ had the usual number of islets of Langerhans, but individual islets showed an increase in number of cells containing numerous cytoplasmic granules which were eosinophilic in $\mathrm{H}$ and $\mathrm{E}$ preparations (Fig. 3), and purple in Gomori's chromium haematoxylin phloxine stains. These were regarded as alpha cells. Pale blue cells in Gomori's chromium haematoxylin phloxine stains, considered to be beta cells, were diminished in number.

Other postmortem findings included hepatic fatty metamorphosis, arteriolar nephrosclerosis and acute tubular necrosis, and pulmonary oedema.

The hypothalamic mass was diagnosed as a neoplasm of mixed mesenchymal and neuroepithelial origin (combined plasmacytoma, lymphoma, ganglioneuroma, and astrocytoma), and the islets of Langerhans were considered to show hyperplasia of alpha cells and hypoplasia of beta cells.

\section{DISCUSSION}

Primary intracranial plasmacytoma, lymphoma, and ganglioneuroma or ganglioglioma were reported in the medical literature (Courville, 1930; Courville and Anderson, 1941; French, 1947; Russell and Rubinstein, 1962; Moossy and Wilson, 1967; Jakumeit et al., 1974), and some arose in the hypothalamus (French, 1947). In our case, a unitary diagnosis cannot be offered because of diversity of the cellular constituents of the tumour. We consider the diagnosis of a neoplasm of mixed mesenchymal and neuroepithelial origin to be most appropriate, because the term covers all types of cells in the lesion.
This category of combined tumours forms $1.6 \%$ of 1028 intracranial neoplasms of our reported series (Shuangshoti and Panyathanya, 1974). We have described previously two cases of mixed neoplasm containing lymphomas, and discussed the mode of their occurrence (Shuangshoti and Netsky, 1971a, b).

Teratoma must be differentiated from the present hypothalamic tumour because of its location in the midline and multiplicity of cellular components. No elements in the mass are foreign to the brain; hence, it is not a teratoma (Willis, 1951). We regard the plasma cells and lymphocytes to be within the line of microglia. Primary neuraxial plasmacytoma and lymphoma can be recognized as variants of microglioma.

Hypothalamic lesions may produce diversified symptoms and signs such as hyperphagia, diabetes mellitus, disturbances in regulation of the body temperature and sleep pattern, diabetes insipidus, episodic savage behaviour, hypogonadism, hypothyroidism, and hypoadrenalism.o These manifestations may occur singly or in combination. Reeves and Plum (1969) reported $\underset{\$}{\mathbb{P}}$ 20 year old woman with a hamartoma at the base of the diencephalon which destroyed the ventro? medial hypothalamus bilaterally as well as the median eminence. The patient had hyperphagias obesity, and a lower threshold for aggressive behaviour. A five year old girl described by Killeffer and Stern (1970) had severe damage of the anterior and middle portions of the hypothalamus with partial preservation of the more caudal part after removal of a craniopharyngioma. The child, during a period of survival of six years, suffered deficiency in the regulation of the body fluid, episodic savage behaviour, hyperphagia, irregular sleep pattern, and inconstant body temperature. According to Ranson and Clark (1959), bilateral lesions of the caudal part of the lateral hypothalamic region produce somnolence, and inconstant body temperature which varies with the environmental temperature. A lesion of the anterior hypothalamic region, on the other hand, may result in hyperthermia. Destruction of the supraoptic nuclei is followed by the occurrence of diabetes insipidus.

We are unable to locate definitely the area of damage in our patient because of the extensive involvement of the entire hypothalamus by the tumour. However, we suggest that the lesion has 
induced hyperphagia. The hyperplasia of the alpha cells and hypoplasia of the beta cells of the islets of Langerhans, and hyperphagia produced the diabetes mellitus. Excessive accumulation of adipose tissue in association with hyperphagia requires increased amounts of insulin which leads to deficiency of this hormone and consequent hyperglycaemia (Hausberger et al., 1964). In addition, the alpha cells produce glucagon, the hyperglycaemic-glycogenolytic hormone which antagonizes the effects of insulin. McGavran et al. (1966) reported a diabetic patient with alpha cell carcinoma of the islets of Langerhans and hepatic metastasis. The primary cancer contained large amounts of glucagon. Experimentally, certain toxic substances such as alloxan destroy the beta cells of the islets of Langerhans and leave the alpha cells intact; diabetes mellitus develops in such conditions (Bailey and Bailey, 1943).

Although Vejjajiva et al. (1969) reported a non-diabetic patient with chronic sustained hypernatraemia, presumably induced by a hypothalamic pinealoma, we are unable to conclude that the hypernatraemia of our patient was caused solely by the hypothalamic mixed tumour. A lengthy study of her electrolytes was lacking to indicate that the hypernatraemia was chronic. Moreover, an increased serum sodium may result if patients with diabetic coma are treated mainly with insulin and saline solution (Schoolman et al., 1955).

We are grateful to Dr Somsak Dhechakaisaya, Professor and Head of the Department of Pathology, who gave us permission to report this case.

\section{REFERENCES}

Bailey, C. C., and Bailey, O. T. (1943). The production of diabetes mellitus in rabbits with alloxan. Journal of the American Medical Association, 122, 1165-1166.

Courville, C. B. (1930). Ganglioglioma, tumor of the central nervous system: review of the literature and report of two cases. Archives of Neurology and Psychiatry, 24, 439-491.

Courville, C. B., and Anderson, F. M. (1941). Neuro-gliogenic tumors of the central nervous system: report of two additional cases of ganglioglioma of the brain. Bulletin of Los Angeles Neurological Society, 6, 154-176.

French, J. D. (1947). Plasmacytoma of the hypothalamus: clinical-pathological report of a case. Journal of Neuropathology and Experimental Neurology, 6, 265-270.

Hausberger, F. X., Broadhead, C. L., Jr, and Hausberger, B. C. (1964). Obesity and diabetes mellitus in a rat with hypothalamic lesions: report of a case and review of the literature. Acta Endocrinologica, 45, 600-604.

Jakumeit, K., Zimmermann, V., and Guiot, G. (1974). Intrasellar gangliocytomas: report of four cases. Journal of Neurosurgery, 40, 626-630.

Killeffer, F. A., and Stern, W. E. (1970). Chronic effects of hypothalamic injury: report of a case of near total hypothalamic destruction resulting from removal of a craniopharyngioma. Archives of Neurology, 22, 419-429.

McGavran, M. H., Unger, R. H., Recant, L., Polk, C., and Levin, M. E. (1966). Glucagon secreting alpha cell carcinoma of the pancreas. New England Journal of Medicine, 274, 1408-1413.

Moossy, J., and Wilson, C. B. (1967). Solitary intracranial plasmacytoma. Archives of Neurology, 16, 212-216.

Ranson, S. W., and Clark, S. L. (1959). The Anatomy of the Nervous System: Its Development and Function, 10th edn, pp. 307-311. Saunders: Philadelphia.

Reeves, A. G., and Plum, F. (1969). Hyperphagia, rage, and dementia accompanying a ventromedial hypothalamic neoplasm. Archives of Neurology, 20 616-624.

Russell, D. S., and Rubinstein, L. J. (1962). Ganglioglioma: a case with a long history and malignant evolution. Journal of Neuropathology and Experimental Neurology, 21, 185193.

Schoolman, H. M., Dubin, M. S., and Hoffman, W. S. (1955). Clinical syndromes associated with hypernatremia. Archives of Internal Medicine, 95, 15-23.

Shuangshoti, S., and Netsky, M. G. (1971a). Neoplasms of mixed mesenchymal and neuroepithelial origin: relation to 'monstrocellular sarcoma' or 'giant-celled glioblastoma'. Journal of Neuropathology and Experimental Neurology, 30, 290-309.

Shuangshoti, S., and Netsky, M. G. (1971b). Brain tumor of mixed mesenchymal and neuroepithelial origin: case report. Journal of Neurosurgery, 34, 808-813.

Shuangshoti, S., and Panyathanya, R. (1974). Neural neoplasms in Thailand: a study of 2897 cases. Neurology (Minneap.), 24, 1127-1134.

Vejjajiva, A., Sitprija, V., and Shuangshoti, S. (1969). Chronic sustained hypernatremia and hypovolemia in a hypothalamic tumor: a physiologic study. Neurology (Minneap.), 19, 161-165.

Willis, R. A. (1951). Teratomas. In Atlas of Tumor Pathology, section 3, fascicle 9, p. 9. Armed Forces Institute of Pathology: Washington, D.C. 